\title{
As funções reservadas ao Município de Cariré/CE no Plano de Desenvolvimento Urbano Integrado da Região Metropolitana de Sobral (PDUI/RMS)
}

\section{The functions reserved for the Municipality of Cariré, State of Ceará, in the Integrated Urban Development Plan for the Metropolitan Region of Sobral (PDUI/RMS)}

\section{Las funciones reservadas al Municipio de Cariré, Estado de Ceará, en el Plan Integrado de Desarrollo Urbano de la Región Metropolitana de Sobral (PDUI / RMS)}

Antonio Veiga Rodrigues ${ }^{1}$ https://orcid.org/0000-0002-0061-6871

Glauciana Alves Teles² https://orcid.org/0000-0002-6952-8837

\footnotetext{
${ }^{1}$ Universidade Estadual Vale do Acaraú - UVA, Sobral, Ceará, Brasil. E-mail: antonio.veiga96@gmail.com

2 Universidade Estadual Vale do Acaraú - UVA, Sobral, Ceará, Brasil. E-mail: glauciana_teles@uvanet.br
}

Recebido em: 17/09/2021

Aceito para publicação em: 20/12/2021

\section{Resumo}

A Região Metropolitana de Sobral (RMS) foi a terceira região metropolitana institucionalizada no Estado do Ceará, em dezembro de 2016. Em 2018, foi apresentado o relatório final do Plano de Desenvolvimento Urbano Integrado (PDUI), trazendo as diretrizes para o desenvolvimento urbano e regional da unidade territorial. A RMS é composta por 18 municípios, sendo a cidade de Sobral sua sede metropolitana, além de ser considerada um dos principais centros urbanos cearenses. Nesse contexto, Cariré, um dos dezoito municípios destaca-se possui características territoriais particulares que o evidenciam de suma importância na gestão territorial da RMS, possuindo as funções logística e comercial. O artigo apresenta uma análise das funções de Cariré no contexto da reestruturação territorial da RMS.

Palavras-chave: Planejamento territorial; Região Metropolitana de Sobral; Reestruturação territorial; Cariré.

\begin{abstract}
The Metropolitan Region of Sobral (RMS) was the third institutionalized metropolitan region in the State of Ceará, in December 2016. In 2018, the final report of the Integrated Urban Development Plan (PDUI) was presented, providing guidelines for urban development and regional of the territorial unit. The RMS is made up of 18 municipalities, the city of Sobral being its metropolitan headquarters, in addition to being considered one of the main urban centers in Ceará. In this context, Cariré, one of the eighteen municipalities stands out, has particular territorial
\end{abstract}

Geopauta, Vitória da Conquista ISSN: 2594-5033, V. 5, n.4, 2021, e9517

Este é um artigo de acesso aberto sob a licença Creative Commons da CC BY 
RODRIGUES, A.V.; TELES, G.A.

characteristics that make it extremely important in the territorial management of the RMS, having both logistical and commercial functions. The article presents an analysis of Cariré's functions in the context of the territorial restructuring of the RMS.

Keywords: Territorial planning; Metropolitan Region of Sobral; Territorial restructuring; Cariré.

\section{Resumen}

La Región Metropolitana de Sobral (RMS) fue la tercera región metropolitana institucionalizada en el Estado de Ceará, en diciembre de 2016. En 2018 se presentó el informe final del Plan Integrado de Desarrollo Urbano (PDUI), que brinda lineamientos para el desarrollo urbano y regional de la unidad territorial. La RMS está conformada por 18 municipios, siendo la ciudad de Sobral su sede metropolitana, además de ser considerada uno de los principales núcleos urbanos de Ceará. En este contexto, Cariré, uno de los dieciocho municipios que se destaca, tiene características territoriales particulares que lo hacen sumamente importante en la gestión territorial de la RMS, teniendo funciones tanto logísticas como comerciales. El artículo presenta un análisis de las funciones de Cariré en el contexto de la reestructuración territorial de la RMS.

Keywords: Planificación territorial; Región Metropolitana de Sobral; Reestructuración territorial; Cariré.

\section{Introdução}

As regiões metropolitanas no contexto brasileiro assumem papéis e significados de acordo com a forma com que são abordadas em estudos sobre urbanização e desenvolvimento regional. Na Geografia temos observado com maior frequência estudos do processo de metropolização do espaço nas metrópoles e suas regiões metropolitanas, enquanto há menos frequência nos estudos que levam em consideração o planejamento territorial como objeto de transformações socioterritoriais em regiões metropolitanas que não possuem uma metrópole como sede metropolitana, algo que nosso estudo busca contribuir.

A Região Metropolitana de Sobral, localizada na porção noroeste do estado do Ceará, foi a última região metropolitana a ser institucionalizada no Brasil, até então. Possui como sede metropolitana a cidade de Sobral, importante centro urbano cearense que polariza cidades pequenas de seu entorno e assume papel de centralidade em diversas escalas. Essa cidade possui relevância histórica devido a 
sua posição estratégica, entre a capital cearense, por estar próxima à Serra da Ibiabapa e ao Estado do Piauí. Atualmente, essa cidade representa uma capital regional de nível C (IBGE, 2020), tendo no comércio, nos serviços, no ensino superior e na indústria calçadista, seus principais atrativos econômicos.

O planejamento da RM de Sobral foi iniciado no ano de 2017 quando houve os primeiros passos para a construção do Plano de Desenvolvimento Urbano Integrado (PDUI). Esse documento é um instrumento de desenvolvimento urbano e regional amparado pelo Estatuto da Metrópole (2015). Divulgado em 2018, à sociedade civil através do relatório final, esse documento propõe uma série de iniciativas que a gestão metropolitana deve tomar a médio prazo. Uma delas é uma proposta de reestruturação territorial das cidades e municípios que compõe essa unidade territorial.

Um dos municípios que recebe destaque no referido cenário intrametropolitano é Cariré, situado ao sul da cidade de Sobral. Esse município é um importante ponto de destaque, pois possui uma posição estratégica por situar-se na região central do território da RMS. Nesse quesito, duas funções foram incorporadas ao município no PDUI: a logística e a comercial. Desse modo, lançamos a seguinte questão que norteou as nossas reflexões: quais os papéis assumidos por Cariré na atual configuração da RMS e que funções são potenciais na sua reestruturação territorial que dê subsídios à integração ao PDUI?

Diante disso, nosso artigo propõe uma análise crítica sobre as funções do município de Cariré no contexto do planejamento territorial da Região Metropolitana de Sobral, a fim de contribuir para a discussão sobre o desenvolvimento regional da unidade territorial. É parte das reflexões desenvolvidades em nossa pesquisa de mestrado institulada "Cidades médias no contexto metropolitano brasileiro: institucionalização e planejamento territorial da Região Metropolitana de Sobral/CE" defendida em 2020, no curso de Mestrado Acadêmico em Geografia (MAG) da Universidade Estadual Vale do Acaraú (UVA). 
Para a construação do presente texto, utilizamos como procedimentos metodológicos, revisão bibliográfica sobre os principais temas a questão metropolitana brasileira consultando autores como Lencione (2006) e Firkowski (2013), dentre outros; sobre a RM de Sobral, tendo amparado nas legislações estaduais e no estudo de Rodrigues (2020); e análise crítica a partir da leituira do documento PDUI/RMS (2018), no que se refere à reestruturação territorial do município de Cariré, sob uma perspectiva da ciência geográfica. Como aporte às análises, foram realizadas, ainda, consultas em sítios eletrônicos e documentos oficiais do IBGE $(2018 ; 2020)$ e do IPECE (2015), além de trabalhos de campo no município.

Para uma melhor compreensão o artigo está estruturado da seguinte maneira: esta introdução; uma discussão breve sobre a criação das regiões metropolitanas no país; discussão sobre do território da RM de Sobral e sobre a proposta de reestruturação territorial; e as funções municipais de Cariré no contexto do planejamento territorial; e por fim, as considerações finais e referências utilizadas na pesquisa.

\section{Breve histórico da criação de regiões metropolitanas no Brasil}

A urbanização brasileira se deu de forma rápida o que ocasionou uma série de problemáticas oriundas da ausênica de planejamento urbano e de gestões que debandassem a resolução dos já conhecidos problemas econômicos e socioespaciais. Se ao contrário das regiões metropolitanas criadas na década de 1970, a partir da década de 1980, com a promulgação da nova Constituição Federal de 1988, os Estados ganharam autonomia para a criação de suas próprias regiões metropolitanas, causando o aumento no quantitativo de tais unidades regionais, mas também na complexidade do trato do metropolitano.

Segundo Lencione (2006), a região metropolitana é historicamente associada à metrópole e ao processo de metropolização, ou seja, da complexidade das funções urbanas superiores, da influência regional, da extensão física, do consumo e cultura, dentre outros, que representam a complexidade do fenômeno urbano. 
No Brasil contemporâneo, essa associação não segue à risca essa concepção, já que existem regiões metropolitanas onde há a inexistência de uma metrópole ou do processo de metropolização. Isso se dá a possibilidade de centros regionais ou sub-regionais, que não possuem complexidade de funções superiores e nem exercem influência além de seus limites regionais, de se tornarem sedes metropolitanas, ou seja, de serem, de fato, núcleos metropolitanos, apesar da pouca dinâmica urbana.

Essa questão faz Firkowski (2013) afirmar que há um “divórcio" entre região metropolitana e metrópole.

[...] nem todas as unidades institucionalizadas enquanto "região metropolitana" decorrem efetivamente do processo de metropolização. Assim, no Brasil, parte das regiões metropolitanas se aproxima mais de um recorte regional convencional, sem qualquer evidencia de características metropolitanas, resultando no divórcio entre metropolização e região metropolitana, bem como em seus respectivos processos constitutivos (FIRKOWSKI, 2013, p. 35).

A influência da política regional também é decisiva para a criação dessas unidades, por exemplo, devido aos incentivos para o desenvolvimento de projetos estruturais do planejamento oriundos do Estado.

No entanto, mesmo que isso seja levado em consideração para a discussão conceitual e para a discussão, é evidente que as regiões metropolitanas, na atualidade, são unidades de planejamento territorial nas suas diversas escalas e contextos regionais. Ou seja, mesmo que uma região metropolitana não apresente uma metrópole, ela possui uma cidade média ou pequena que desempenha certa complexidade urbana e econômica que remete à possibilidade de planejamento objetivando o desenvolvimento socioeconômico, assim como pensa Soares (2015).

Segundos dados oficiais do IBGE (2018), até o ano de 2016, existem setenta e quatro regiões metropolitanas institucionalizadas no território nacional, estando presente em quase todas as unidades federativas, com exceção do Mato Grosso do Sul e do Acre. Em questão do quantitativo de RMs, as regiões Nordeste e Sul possuem o maior número, sendo, respectivamente, 31 e 21 regiões metropolitanas; já 
a região Sudeste, historicamente a mais urbanizada, possui 10; enquanto o Norte e Centro-Oeste possuem 10 e 2.

Esses dados se tornam importantes, pois demonstram a força das políticas regionais na questão metropolitana, onde, por exemplo, a região Nordeste possui o maior número de RMs institucionalizadas. Se levarmos em consideração o quantitativo por estado, se torna mais evidente essa política. Paraíba e Santa Catarina são os que mais possuem esse tipo de unidade regional, apresentando, respectivamente, 12 e 10 unidades. Se consideramos os números, quase todos os centros regionais e/ou de importância sub-regional, são núcleos de regiões metropolitanas, o que deixa evidente a discussão levantada anteriormente.

Rodrigues (2020) levanta, a partir do REGIC (2008), a hierarquização das sedes metropolitanas brasileiras ${ }^{3}$, a saber: existem 12 metrópoles (15, segundo os novos dados do IBGE, no ano de 2020), 37 capitais regionais, 18 centros subregionais, 10 centros de zona e 5 centros locais. Portanto, as capitais regionais, entre capitais estaduais e cidades médias, constituem a maior parte das sedes metropolitanas, em contraposição da existência de 15 metrópoles. Há ainda cidades que são consideradas pequenas, com população inferior a 50 mil habitantes que estão como núcleo de suas respectivas regiões metropolitanas. Há de se considerar que existem sedes metropolitanas que são consideradas centros locais, ou seja, cidades que sequer exercem poder de influência para além de seus limites territoriais.

Segundo Firkowski (2013), as regiões metropolitanas brasileiras se apresentam mais como recortes regionais de planejamento e ordenamento territorial do que necessariamente regiões metropolitanas. No entanto, tal afirmação tem que ser usada com atenção na discussão do metropolitano, levando em consideração as suas funcionalidades dentro da rede urbana estadual e nacional.

É nesse contexto que se insere a Região Metropolitana de Sobral, tendo uma cidade média como sede metropolitana, e que apresenta um Plano de

\footnotetext{
${ }^{3}$ Ainda no ano de 2020, o IBGE elevou as cidades de Campinas (SP), Vitória (ES) e Florianópolis (SC), a categoria de metrópoles. Sendo assim, a nova configuração ficaria da seguinte forma: 15 metrópoles; 34 capitais regionais, 18 centros sub-regionais, 10 centros de zona e 5 centros locais.

Geopauta, Vitória da Conquista ISSN: 2594-5033, V. 5, n.4, 2021, e9517
} 
Desenvolvimento Urbano Integrado (PDUI) com proposta de elaborae uma série de mudanças socioterritoriais que almejam um desenvolvimento integrado dos municípios que a constituem.

\section{Região Metropolitana de Sobral e a proposta de reestruturação territorial}

Institucionalizada no dia 27 de dezembro de 2016, através da Lei Complementar Estadual nº 168/2016, a Região Metropolitana de Sobral se localiza no Norte de Sobral (ver mapa 01), tendo a cidade de Sobral como sede metropolitana, contando com 18 municípios, todos da região imediata de Sobral. É composta pelos seguintes municípios: Alcântaras, Cariré, Coreaú, Forquilha, Frecheirinha, Graça, Groaíras, Massapê, Meruoca, Moraújo, Mucambo, Pacujá, Pires Ferreira, Reriutaba, Santana do Acaraú, Senador Sá, Sobral e Varjota.

Mapa 01 - Localização da Região Metropolitana de Sobral - RMS.

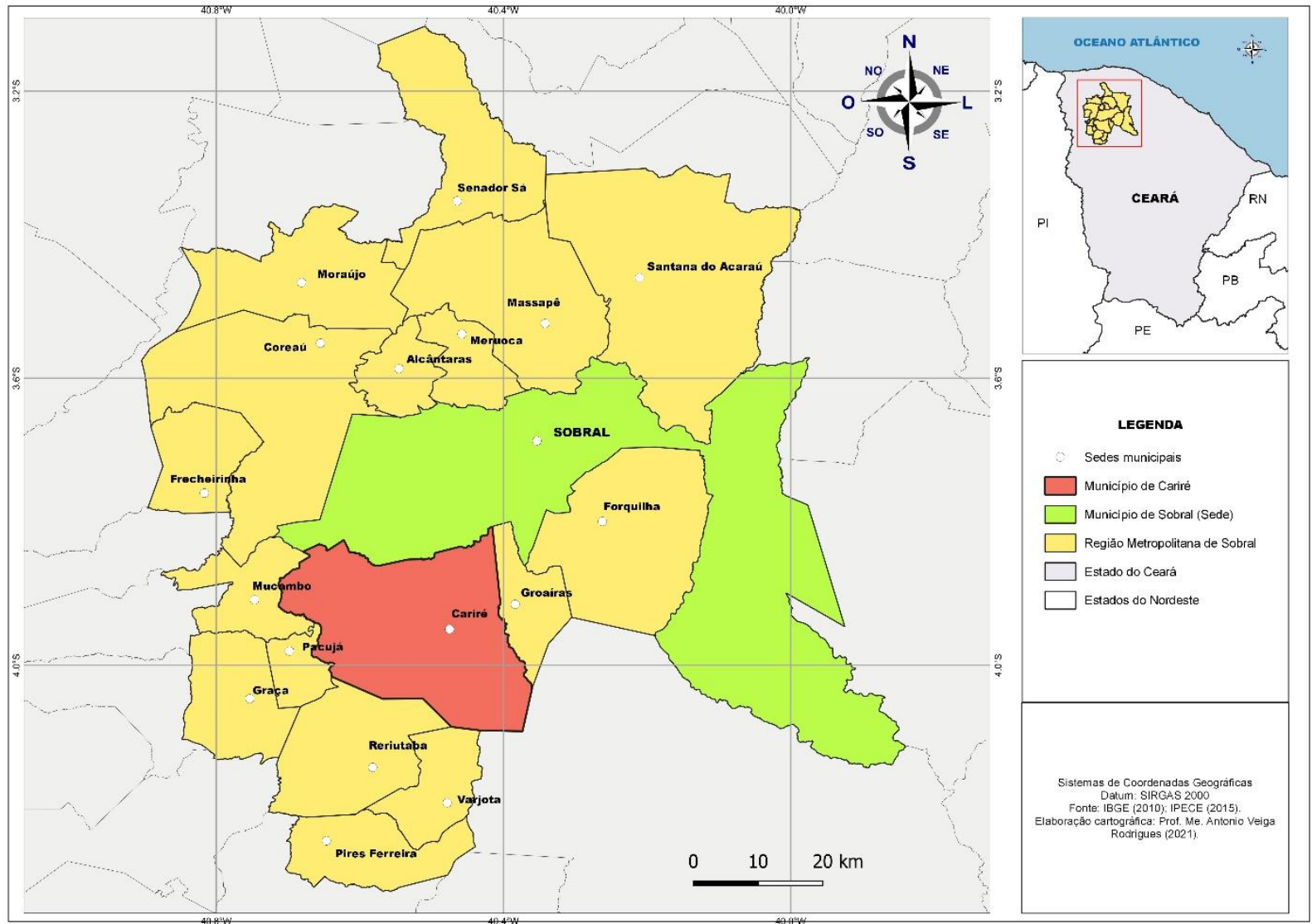

Fonte: IBGE (2010); IPECE (2015). Elaboração: Rodrigues (2021).

Assim como outros casos, a RM de Sobral possui uma capital regional de nível C como sede metropolitana, ou seja, apesar de existir formalmente uma região metropolitana, a região ainda não possui dinâmicas metropolitanas e nem possui 
relações de integração. Segundo Rodrigues (2020), o que existe é na verdade uma situação de dependência entre os demais municípios para com Sobral.

Das 18 cidades que compõe a RMS, 17 podem ser consideradas como pequenas cidades, todas possuindo população inferior aos 20 mil habitantes, segundo a estimativa populacional para o ano de 2018 (IBGE, 2018). Isso quer dizer que elas possuem dinâmicas urbanas com pouca complexidade, apresentando-se como centros locais, exercendo sua influência apenas para seu território municipal e áreas rurais de municípios limítrofes.

Essa característica é relevante na construção do Plano de Desenvolvimento Urbano Integrado (PDUI) da RM de Sobral no que concerne à proposta de reestruturação territorial que vislumbra mudanças pertinentes para a construção de uma região metropolitana e o desenvolvimento regional integrado. Segundo o Estatuto da Metrópole (BRASIL, 2015; 2018), em seu Art. 2º, inciso VI, o PDUI é

Um instrumento que estabelece, com base em processo permanente de planejamento, viabilização econômico-financeira e gestão, as diretrizes para o desenvolvimento territorial estratégico e os projetos estruturantes da região metropolitana e aglomeração urbana.

O PDUI da RM de Sobral foi um dos primeiros exemplares a pôr em prática as orientações propostas pelo Estatuto da Metrópole $^{4}$ no Ceará, estando os documentos das demais regiões metropolitanas cearenses em processo de construção.

Levando em consideração o planejamento e desenvolvimento territorial, os municípios foram sub-regionalizados a partir de características em comum para melhor haver uma gestão e organização. Ainda em 2018, o consórcio responsável pela confecção do PDUI propôs a criação de cinco sub-regiões: Noroeste, Norte, Central, Sudoeste e Sul.

A sub-região Noroeste é composta pelos municípios de Frecheirinha, Coreaú e Moraújo; a Norte pelos municípios de Senador Sá, Massapê e Santana do Acaraú; a

\footnotetext{
${ }^{4}$ Para mais informações sobre o processo de construção do PDUI/RMS, ver Rodrigues (2020); ou ainda acessar os documentos através do endereço: http://www.pduisobral.com.br/

Geopauta, Vitória da Conquista ISSN: 2594-5033, V. 5, n.4, 2021, e9517
} 
Central por Sobral e Forquilha; a Sudoeste é composta por Graça, Mucambo e Pacujá; e a Sul por Cariré, Groaíras, Reriutaba, Varjota e Pires Ferreira. Dada a complexidade de situações, ainda na proposta de reestruturação territorial, os municípios foram agrupados por suas potencialidades econômicas, levando em consideração as atividades que já possuem certo desenvolvimento e estrutura em funcionamento.

Sendo assim, as cidades e municípios da Região Metropolitana de Sobral foram apresentadas a partir de sua capacidade de centralidade e pela principal atividade econômica a ser desenvolvida, a saber: centralidades de indústria, de comércio e serviços, turismo, logística e as centralidades locais ${ }^{5}$.

A cidade de Sobral é a única centralidade regional metropolitana, sendo a sede da unidade. Sendo uma das maiores economias cearenses, assim como detentora de uma forte indústria, atividades comerciais, serviços educacionais e de saúde, dentre outros, é classificada como centralidade de gestão, indústria, comércio e serviços e turismo. No cenário regional, a única outra cidade que possui capacidade de centralidade acima das demais é Massapê, que é classificada como sendo a centralidade sub-regional metropolitana, sendo os dois centros urbanos mais importantes da RMS.

No que se refere às centralidades sub-regionais de indústria, além de Sobral, Forquilha, Frecheirinha e Massapê são assim classificadas. Dentre estas três, podemos dizer que Frecheirinha se destaca por ter uma rede de pequenas e médias indústrias, se constituindo como uma APL de confecção de roupas íntimas femininas. As demais possuem algumas indústrias, mas sem relevante expressão na composição de suas economias municipais.

As centralidades sub-regionais de comércio e serviços, são àquelas que possuem a maior potencialidade do setor e que conseguem exercer suas centralidades para além de seus territórios municipais, são elas: Massapê, Forquilha, Frecheirinha e Cariré. Todas elas possuem atividades comerciais em pleno

\footnotetext{
${ }^{5}$ É levado em consideração as potencialidades secundárias que são àquelas ligadas a atividades como agroindústria, turismo, dentre outras, que estão localizadas em áreas não urbanizadas.

Geopauta, Vitória da Conquista ISSN: 2594-5033, V. 5, n.4, 2021, e9517
} 
desenvolvimento, assim como possuem serviços importantes como, por exemplo, a educação profissionalizante integrada ao ensino médio, e os bancários, etc.

As centralidades sub-regionais de turismo são os municípios que possuem características naturais e culturais que merecem destaque, são elas: Alcântaras e Meruoca (localizadas na Serra da Meruoca), Mucambo, Graça e Reriutaba (que possuem áreas localizadas no sopé da Serra da Ibiapaba), Pacujá (turismo histórico/cultural), Santana do Acaraú e Varjota (Rio Acaraú), além de Massapê que possui áreas da Serra da Meruoca. Dentre estes, além de Sobral que conta com sítios arquitetônicos tombados, o que já possui estrutura considerável para a atividade turística é o município de Meruoca.

Já a única centralidade sub-regional de logística é Cariré. Esse foi escolhido, como objeto de análise, por apresentar uma sub-rede de rodovias e estradas que a liga com diversas cidades da RMS e do Norte cearense. São duas rodovias estaduais e uma federal que é colocada como local que pode servir como alternativa à Sobral a partir de suas interligações rodoviárias.

Há ainda os municípios dos quais nenhuma atividade se destacou o suficiente para que eles fossem classificados em alguma das já mencionadas, sendo assim chamadas de centralidades locais, ou seja, àquelas cidades que possuem centralidade limitada, muitas vezes perdendo centralidade de atividades básicas para outros municípios limítrofes. São quatro municípios com essa classificação: Moraújo, Senador Sá, Groaíras e Pires Ferreira.

Segundo Rodrigues (2020), apesar do PDUI/RMS (2018) apresentar uma proposta de reestruturação, o que é necessário, em alguns casos, é haver uma estruturação das atividades econômicas e da própria estrutura física das cidades e municípios para desempenharem tais funções no contexto regional. $\mathrm{O}$ autor ainda levanta a questão que algumas funções foram minimizadas como, por exemplo, a centralidade do comércio da cidade de Varjota, a possibilidade do desenvolvimento do turismo em Pires Ferreira, a questão da indústria para além dos municípios que 
desempenham essa função, assim como as fragilidades naturais e econômicas das centralidades de turismo.

Dentre os 18 municípios que constituem a Região Metropolitana de Sobral, Cariré merece destaque como a única centralidade sub-regional de logística, sendo uma característica potencial para o desenvolvimento, não somente do município, mas também na questão da integração intrarregional.

\section{Características territoriais de Cariré}

Localizado na porção Noroeste do Estado do Ceará, o municipio de Cariré está situado na chamada planície sertaneja cearense e possui predominância do clima semiárido com temperaturas que variam entre $25^{\circ}$ e $28^{\circ}$ (IPECE, 2017). Com uma extensão territorial de $756,9 \mathrm{~km}^{2}$, esse município possui importância no contexto regional por possuir rios que integram as bacias hidrográficas do rio Acaraú e do rio Jaibaras, além do Açude Taquara importantes recursos hidrícos na porção Noroeste.

Possuindo uma população de pouco mais de 18,4 mil habitantes (IBGE, 2021), Cariré se configura como um dos municípios que "orbitam" ao redor da cidade de Sobral, estando na sua área de intermediária e imediata (IBGE, 2020), o que ocasiona deslocamentos cotidianos para essa cidade em busca de serviços básicos e especializados como educação e saúde, além das atividades comerciais. Ao contrário da tendência da urbanização brasileira, esse município possui a maior parte da população residindo na zona rural, algo que se torna uma peculiaridade no contexto intrarregional. Segundo IBGE (2010), 45,24\% da população municipal era considerada urbana, residindo na sede municipal e demais sedes distritais, enquanto $54,76 \%$ residia nas áreas rurais.

Em seu passado, esse município foi um produtor algodoeiro, sendo a cotonicultura sua principal atividade econômica, tendo na década de 1950 a 1980, seu ápice econômico que acabou resultando no aumento populacional, no desenvolvimento urbano e na construção da estrada de ferro que ligava a cidade de Sobral a Ipu (MEDEIROS, 2000). Esses dois fatores - estrada de ferro e a produção 
algodoeira, foram fundamentais na construção de um município que desempenhava papel fundamental na logística ferroviária da região do Noroeste cearense.

O ápice do período do algodão no Município foi durante as décadas de 1950 a 1980, quando a cidade se transformou num centro urbano relevante, contando com cerca de 19 mil habitantes, seu auge populacional até os dias atuais. Filinto (2009), em seu livro sobre a história municipal da cidade reflete sobre as várias mudanças na estrutura física e equipamentos urbanos como o primeiro ponto comercial da cidade, a construção do mercado público municipal, a construção da primeira igreja, a construção das primeiras residências.

No entanto, com a quebra do sistema produtivo do produto no semiárido, muitos municípios passaram por problemas de ordem socioeconômica, causando graves crises, pois estes eram dependentes dessa produção algodoeira. Um desses foi Cariré que, nas décadas seguintes, viu sua população diminuir e a migração para grandes centros urbanos do país aumentar (MEDEIROS, 2000).

Nos dias atuais, o município desempenha funções comercial e de serviços com capacidade de centralizar somente partes da área do próprio território. Seu comércio que apesar de diversificar-se na última década, ainda sofre forte influência da cidade de Sobral, dada a relativa curta distância e a facilidade de transportes alternativos. Isso impacta, direta e indiretamente, na configuração dos setores econômicos locais.

Segundo dados do IPECE (2017), o Produto Interno Municipal (PIB) é composto da seguinte forma: 81,85\% é oriundo do setor de serviços; a Agropecuária desempenha 14,18\% deste; e a indústria com somente 3,97\%. Na questão do emprego formal, a administração pública ainda é a maior geradora de trabalho (635); seguido pelo setor de serviços (157); a indústria de transformação (71); dentre outros que representam números baixos de emprego formal.

A atividade industrial é pequena como demonstrado pela sua participação no PIB municipal, sendo em sua maioria pequenas fábricas locais que possuem 
poucos empregados. A maior indústria atualmente do município é uma fábrica ceramista que emprega algumas dezenas de empregados formais.

Como podemos observer, Cariré possui problemáticas socioeconômicas como a maioria dos municípios cearenses e brasileiros, estando ainda refém dos empregos gerados pela administração pública, pelos programas sociais do Governo Federal e outros benefícios como das aposentadorias.

A partir do ano de 2016, Cariré passou a integrar a Região Metropolitana de Sobral, possuindo importância na configuração intrametropolitana, pois aparece como a única centralidade sub-regional de logística e é uma das cidades que orbitam a sede metropolitana com possibilidades de investimentos futuros.

Segundo Rodrigues (2020), o município possui capacidade de formar um grupo de seletos locais de desconcentração e/ou expansão da atividade industrial na região metropolitana para além Sobral. Esse grupo seria formado pelos municípios de Massapê, Forquilha e Groaíras.

Dada a todas essas características observadas até aqui, Cariré recebeu atenção por parte dos técnicos na elaboração do PDUI. Sua posição geográfica e seu potencial de desenvolvimento econômico são fortes indícios de suas funções dentro do contexto intrarregional.

\section{Cariré e suas funções no contexto do PDUI da Região Metropolitana de Sobral}

\section{Função Logística}

O município em questão possui importante papel dentro do contexto intrarregional sendo considerada a única centralidade sub-regional de logística, assim como desempenha centralidade sub-regional de comércio e serviços (PDUI/RMS, 2018). Apesar de que, em alguns quesitos, Cariré ainda não desempenhe tais funções e não possua estrutura para assumir tal responsabilidade, na atualidade, ele ainda é importante a partir de suas funções urbanas, notadamente na questão dos serviços.

Cariré, historicamente, possui forte ligação com a cidade de Sobral, por vezes, apresentando dependência econômica em relação ao comércio e serviços mais 
complexos, assim como a maioria dos municípios que compõe a região metropolitana.

Contando com uma população municipal de pouco mais de 18 mil habitantes, dos quais 6 mil estão localizados na sede municipal (IBGE, 2010), Cariré pode ser considerada como uma pequena cidade, possuindo modo de vida característico que mistura práticas do mundo rural e do urbano ${ }^{6}$.

Nos últimos anos, a cidade veio a passar por um processo de urbanização que se concretizou nas requalificações em algumas áreas da cidade, a transformando em um local propício para a instalação de negócios de expressão local, assim como uma ligeira reprodução da atividade commercial para outras áreas além do Centro, através da iniciativa dos pequenos empresários da cidade, assim como a instalação de equipamentos urbanos como a escola profissionalizante, serviços do Departamento Estadual de Trânsito, serviços bancários e previdenciários, dentre outros.

Esse impulso de desenvolvimento culminou na classificação da cidade como uma centralidade de logística dentro do PDUI/RMS (2018). Em entrevista realizada, ainda no ano de 2019 com o representante da instância deliberativa do município na construção dos documentos do PDUI, Rodrigues (2020) diz ficou claro que essa função ainda gera dúvidas da própria gestão municipal ${ }^{7}$ no que se refere ao que de fato poderá mudar essa concepção de uma centralidade de logística.

Nesse caso, da logística, como o Plano colocou, eles não explicaram, detalhadamente, o porquê. Mas é por que eles acham que Cariré é meio caminho da Serra da Ibiapaba que saia daquele corredor da BR222, sendo uma segunda opção. Só pra Serra da Ibiapaba pode ir pela 222 que vai pelo Aprazível (Sobral), pelo Mucambo e pode ir pelo Graça (Ladeira da Lapa), além de Cariré, passando por Reriutaba rumo à Guaraciaba do Norte. Saindo de Cariré, se você quiser ir pra Sobral por Groaíras é mais perto. Quer dizer que sai daquele corredor da BR-222, que tem um trânsito muito grande. Pelo que a gente já acompanhou dos trabalhos e das oficinas que já aconteceram do PDUI, eles tem esse pensamento de descentralizar aquele corredor

\footnotetext{
${ }^{6}$ Rodrigues (2020) menciona a criação de bovinos e plantações de milho nas áreas periféricas do periurbano, por exemplo.

${ }^{7}$ É válido mencionar que houve mudanças na composição dos quadros de secretários dos municípios no ano de 2020.
}

Geopauta, Vitória da Conquista ISSN: 2594-5033, V. 5, n.4, 2021, e9517 
BR-222. Então Cariré ele ficou num ponto estratégico que você ir pra Forquilha não é obrigado você passar dentro de Sobral. você sair daqui para os municípios da Serra da Ibiapaba, você não precisa ir pela BR-222 que quando chega na parte dos caminhões o trânsito fica lento. Você tem mais três opções fora a BR-222. Se você quiser ir pra Fortaleza e não quiser ir pela 222, você vai aqui pela Varjota você pega a CE-366 que passa em Canindé pega a 020 e vai até Fortaleza. Acho que essa parte logística, que ainda não está bem definido, deram apenas um paliativo da posição de Cariré é esta8. (ARAÚJO, 2019, informação verbal).

Fica evidente que objetivo da função logística de Cariré está na sua sub-rede de rodovias que a conecta com outros municípios e outros estados, havendo a possibilidade de uma segunda via de acesso que seja uma alternativa à BR-222. Como mencionado na entrevista, Cariré possui duas rodovias estaduais e uma federal, como observado no quadro a seguir.

Quadro 1 - Ligações rodoviárias de Cariré com os municípios da RMS.

\begin{tabular}{|l|l|}
\hline RODOVIAS/ESTRADAS & LIGAÇÕES \\
\hline CE-183/BR-403 & $\begin{array}{l}\text { Sobral (ao norte) em direção ao litoral; Varjota e Pires Ferreira } \\
\text { (ao sul) em direção à Ipu e Crateús. }\end{array}$ \\
\hline CE-329 & $\begin{array}{l}\text { Reriutaba e parte em direção à Guaraciaba do Norte e demais } \\
\text { municípios da Serra da Ibiapaba. }\end{array}$ \\
\hline CE-253 & Mucambo em direção à Ibiapaba (ao oeste); e Groaíras (ao leste). \\
\hline $\begin{array}{l}\text { ESTRADA } \\
\text { CARIRÉ/TAPUIO }\end{array}$ & Distrito de Tapuio. \\
\hline
\end{tabular}

Fonte: Pesquisa direta.

As duas rodovias estaduais se constituem como importantes trechos, a CE329, que conecta os municípios de Cariré e Reriutaba, assim como para os demais municípios da Serra da Ibiapaba; a CE-253, que conectou, recentemente, Cariré aos municípios de Mucambo, o distrito de Cacimbas (Cariré) e Rafael Arruda (Sobral), assim como à Groaíras, no sentido oeste-leste; além da CE 183/BR-403, que foi federalizada, e que liga Crateús ao litoral cearense em Acaraú, que passa por Cariré, a ligando com Varjota, Pires Ferreira, em direção a Ipu, no sentido sul; assim como como é a principal ligação com Sobral, no sentido norte.

Ainda existe um trecho asfaltada que liga a cidade com a sede do distrito de Tapuio, o segundo mais populoso. Esse distrito é um importante produtor de frutas

\footnotetext{
${ }^{8}$ Entrevista dada por Adauto Eleotério Araújo, Entrevista № 1. Entrevista cedida a Antonio Veiga Rodrigues. Cariré/CE, dia 07/06/2019. Fonte: RODRIGUES, 2020.
}

Geopauta, Vitória da Conquista ISSN: 2594-5033, V. 5, n.4, 2021, e9517 
como mamão e banana, contando com a presença de sítios ao longo das margens do Rio Acaraú, importante recurso hídrico municipal.

Estas são as ligações de rodovias asfaltadas, mas existem outras alternativas que também são importantes como, por exemplo, a estrada Alto dos Honório/Cariré que liga a sede municipal como a localidade homônima e para com Pacujá e Reriutaba; a estrada Tapuio/Anil que liga as duas localidades importantes produtoras de frutas; Anil/Jucá que é a ligação com o distrito carireense mais isolado .

Há ainda outros planos relacionados aos anseios do município já pensando na integração regional, que é sobre a ampliação dos trechos rodoviários que dariam maior possibilidade de conexão para Sobral através de uma rodovia pela localidade de Boa Esperança, na porção nordeste do município de Cariré, que inclusive está presente como possibilidade no PDUI/RMS (2018). Há também outras possibilidades como de um trecho rodoviário que pudesse ligar Cariré-Pacujá-Reriutaba também seria uma alternativa de ligação entre as localidades mais distantes.

Uma das características que mais se destacam na configuração do território carireense é que muitos dos distritos e localidades se localizam distantes da sede. $\mathrm{Ou}$ seja, isso acarreta além da perda da centralidade urbana de Cariré como de questões socioeconômicas, pois os moradores passam a consumir em outras cidades. Essa distância pode ser exemplificada como nos casos de Cacimbas que possui relações cotidianas mais intrínsecas com Mucambo do que com Cariré ou ainda a centralidade de Varjota que se insere em localidades do sul-sudeste do município.

A potencialidade logística de Cariré perpassa por duas situações: a integração do próprio município que precisa ser repensada, planejada e articulada; e a integração regional que é proposto nos planos da Região Metropolitana de Sobral.

\footnotetext{
9 Em muitos casos, as localidades mais distantes como Anil, Jucá, Tapuio, dentre outros, utilizam de transportes particulares como automóveis e motocicletas, ou ainda, as "D20s" e "topiques" como transportes alternativos para Cariré ou se deslocar até a sede municipal para conseguir transportes para outras cidades. Para chegar até Sobral, os habitantes precisam chegar em pontos de ônibus localizados em localidades às margens da BR-403 para pegar transportes coletivos alternativos das cidades de Varjota ou Reriutaba.
}

Geopauta, Vitória da Conquista ISSN: 2594-5033, V. 5, n.4, 2021, e9517 
Essas duas situações são desafios inerentes para a gestão municipal, assim como da própria gestão territorial metropolitana lidar.

\section{Função comercial e de serviços}

Além da potencialidade logística, Cariré se destaca ainda por ser uma centralidade de comércio e serviços dentro da sub-região Sul da RMS, em decorrência de sua localização próxima à Sobral e pela estrutura e equipamentos urbanos que a cidade dispõe.

Rodrigues (2020) diz que a centralidade sub-regional comercial de Cariré ainda permanece na virtualidade, ou seja, apesar do que está presente na proposta de reestruturação territorial contida no PDUI/RMS (2018), a cidade, constantemente, perde e/ou compartilha sua centralidade para outras cidades vizinhas como Varjota ${ }^{10}$, Mucambo e Sobral.

Mesmo com essa questão da perda da centralidade para outras cidades em decorrência de uma questão de distância e de gestão, Cariré vem demonstrando um crescimento de sua oferta comercial e de serviços na última década ${ }^{11}$, principalmente pelo fato de investimentos locais e de empreendedores de outros municípios.

O centro comercial tradicional (imagem 01) é o local com maior variedade de estabelecimentos comerciais como o mercado público municipal, mercadinhos, bares, lanchonetes, padarias, lojas de variedades de vestuário e calçados, móveis, os serviços bancários, dentre outros, que ofertam produtos para os habitantes do distrito-sede e dos distritos e localidades mais próximas.

Estes estabelecimentos, que possuem espaços físicos de pequeno porte, em sua maioria, são de comerciantes e empreendedores locais, e que possuem área de influência limitada. Geralmente, aqueles que consomem seus produtos e serviços são os funcionários públicos da Prefeitura local, aposentados e beneficiários dos programas sociais do Governo Federal como o Programa Bolsa Família, dando ênfase que há também a saída de consumidores para outras cidades como Sobral.

\footnotetext{
${ }^{10}$ No caso de Varjota, ver Rodrigues, Sales e Teles (2018).

${ }^{11}$ Para mais informações ver Rodrigues, Sales e Teles (2019).
}

Geopauta, Vitória da Conquista ISSN: 2594-5033, V. 5, n.4, 2021, e9517 
Foto 01 - Vista parcial do mercado público municipal e pontos comerciais no Centro tradicional.

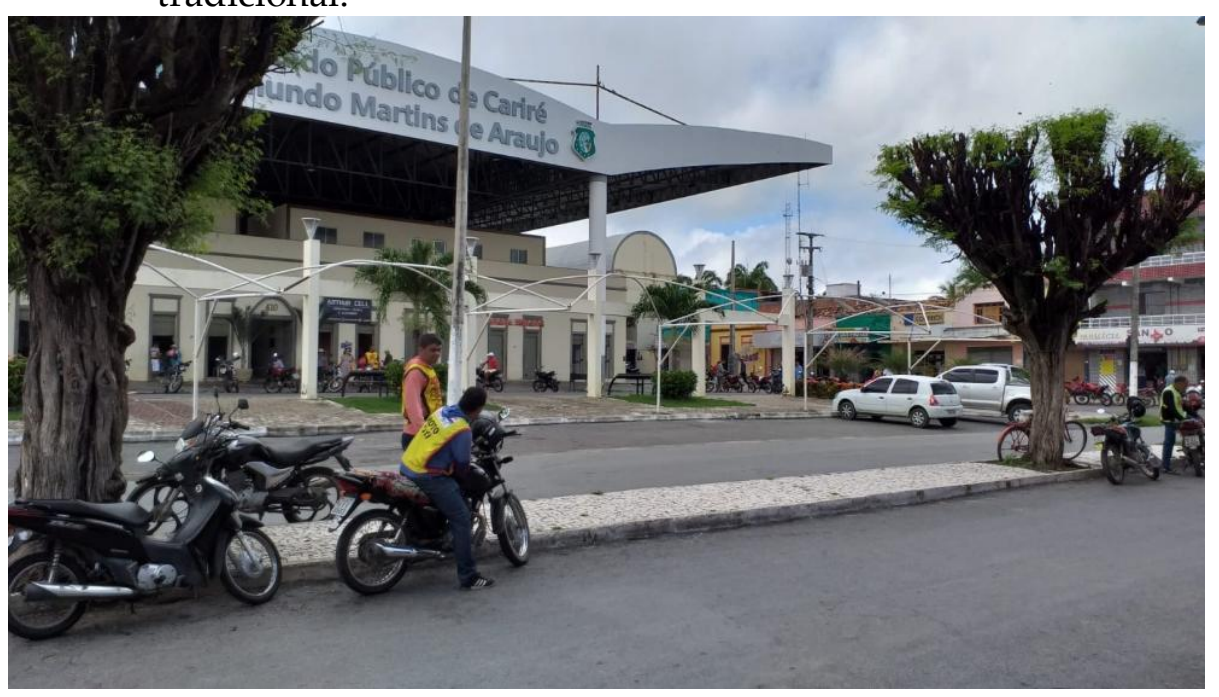

Fonte: Antonio Veiga Rodrigues (2019).

Essa dependência, comum em variados aspectos das pequenas cidades brasileiras, faz com que a cidade de Cariré mantenha essa tradicionalidade do comércio varejista com produtos básicos e que somente conseguem abastecer sua população urbana e demais localidades próximas.

Segundo Gomes e Assis (2008), a proximidade da sede urbana de Cariré com a cidade de Sobral, principal centro urbano do Noroeste Cearense, é uma das possíveis causas para a falta de desenvolvimento econômico do setor no município. Os autores ainda mencionam que isso possibilita que haja relações intermunicipais de maior frequência através dos transportes alternativos que funcionam em intervalos de tempo entre vinte e trinta minutos diariamente.

Todavia, outras cidades que possuem distâncias geográficas menores possuem desenvolvimento comercial mais acentuado a exemplo de Massapê, Forquilha e até mesmo Groaíras. Algumas hipóteses podem ser levadas em consideração: a primeira diz respeito à questão da quebra do sistema produtivo da cotonicultura na década de 1970-1980 que fez com que houvesse um êxodo significativo e que abastou os estabelecimentos comerciais e fabriquetas ali instaladas; a segunda diz respeito a falta de investimentos privados no local, sendo que os pontos comerciais e serviços são, em boa parte, de funcionários públicos ou 
aposentados que residem na cidade, havendo o fechamento de pontos comerciais constantes que não conseguem sobreviver à constante falta de consumidores.

Silva e Holanda (2009), mencionam que o comércio da cidade é majoritariamente marcado pelas atividades comerciais tradicionais como a feira-livre que ainda é a maior forma comercial que atrai consumidores de todas as partes do município. Nos dias atuais ainda é possível ver ambulantes vendendo picolés na rua, vendedores de frutas e vegetais debaixo do mercado público municipal.

O entorno do Mercado Público Municipal Raimundo Martins de Araújo (figura 02), equipamento comercial robusto e de arquitetura "moderna" que foi reformado no ano de 2013-2014, é onde se localiza a feira da cidade. Como mencionado por Santana (2011), é nos dias de feiras que as pequenas cidades ganham vida. Em Cariré também é assim. Pais, filhos, avós, tios vem da zona rural em direção à cidade para comprar mantimentos e produtos diversos que são oferecidos ali, como: frutas, legumes, verduras, vestimentas, calçados, bijuterias, dentre outros.

Foto 02 - Mercado Público Municipal de Cariré.

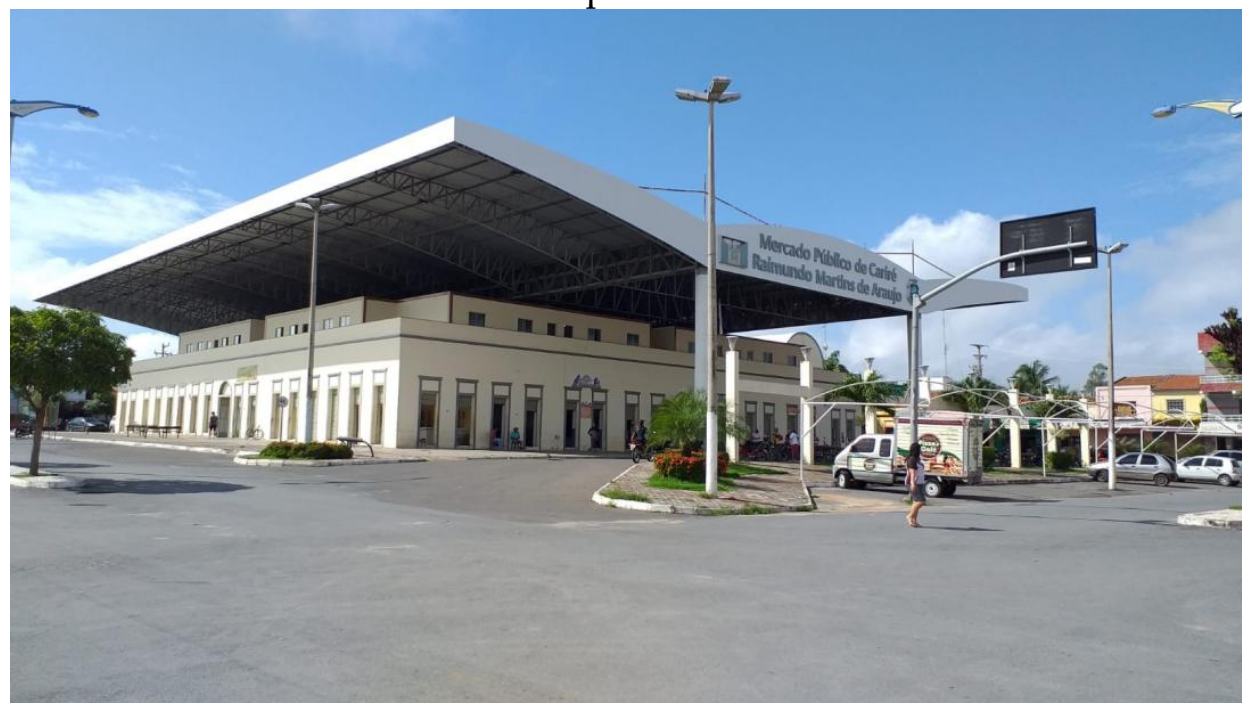

Fonte: Antonio Veiga Rodrigues (2019).

Mas é recentemente na área dos serviços educacionais e de saúde que a cidade vem se destacando nos últimos anos. $\mathrm{Na}$ área educacional, a instalação da Escola Estadual de Educação Profissionalizante Guiomar Belchior Aguiar, inaugurada em 2013, deu novas dinâmicas espaciais à cidade. Alunos de municípios 
vizinhos $^{12}$ vêm diariamente para a cidade para estudar e professores de outros locais também passaram a residir no município. Localizada na rodovia BR-403, no bairro Cariré Velho, se tornou um dos equipamentos urbanos mais importantes do município.

$\mathrm{Na}$ área da saúde, a instalação de algumas clínicas médicas que oferecem serviços que anteriormente não eram ofertados ali. Exames como sanguíneo, ultrassom, endoscopia, de DNA, são encontrados na cidade. Essa diversificação, segundo as ideias de Holanda (2018), faz parte do papel do ensino superior que faz das pequenas cidades locus de novos empreendimentos.

Nesse sentido, as pequenas cidades como Cariré se tornam espaços de transformações que acarretam na inserção de novos tipos de atividades comerciais, de serviços, de empreendimentos locais que antes só podiam ser encontrados nas cidades médias e grandes.

É válido também mencionar o potencial industrial do município. Cariré é um dos cinco municípios que o PDUI/RMS (2018) propõe a instituição de Áreas Estratégicas de Desenvolvimento Industrial e Logístico (AEDIL). Segundo o planejamento territorial, a área propícia à instalação se dá ao longo da BR-403 em direção à Sobral.

Assim como menciona Rodrigues (2020), Cariré junto com outros municípios que "orbitam" a cidade de Sobral são locais propícios para um processo de descentralização da atividade industrial desse centro urbano para outras cidades de seu entorno.

\section{Considerações finais}

No planejamento territorial a nível metropolitano devem ser evidenciadas as potencialidades e vulnerabilidades socioeconômicas do municipio afim de contribuir para as concepções de desenvolvimento urbano e regional da unidade territorial.

\footnotetext{
${ }^{12}$ Podemos citar alunos oriundos de Groaíras, distrito de Macaraú (Santa Quitéria), distrito de Jaibara (Sobral) e distrito de Amanaira (Reriutaba).
}

Geopauta, Vitória da Conquista ISSN: 2594-5033, V. 5, n.4, 2021, e9517 
No caso da Região Metropolitana de Sobral (RMS), mais precisamente de Cariré, algumas considerações devem ser feitas, pois a virtualidade de algumas funções são evidentes. A função logística é um potencial enorme no contexto intrarregional, sendo a única centralidade deste tipo; já que na questão da atividade comercial e dos serviços, observamos a tradicionalidade comercial da cidade, apesar de alguns avanços nos últimos anos.

Mesmo assim, o município possui um potencial ímpar dentro da RM de Sobral por ser possuidor de um território vasto e que está posicionado próximo à Sobral e por um nó de entroncamento de rodovias importantes que são base para uma centralidade de logística regional.

Diante do observado, os desafios para a implementação de projetos estruturantes para afirmar tais potencialidades se constituirão um verdadeiro desafio para a gestão territorial da RMS, pois a falta de infraestrutura para atender as proposições do PDUI é o que realmente um empecilho no desenvolvimento regional da unidade.

Esperamos que tal artigo seja utilizado pelas autoridades locais e intrarregionais como subsidio às discussões do planejamento territorial na concepção de um desenvolvimento que contemple a todos direta e indiretamente.

\section{Referências Bibliográficas}

BRASIL. Lei n ${ }^{\mathrm{o}}$ 13.089, 12 de janeiro de 2015. Institui o Estatuto da Metrópole, altera a Lei n⿳0 $\mathbf{1 0 . 2 5 7}$, de 10 de julho de 2001, e dá outras providências. Brasília-DF: Palácio do Planalto, jan. 2015. Disponível em: http://www.planalto.gov.br/ccivil_03/_ato20152018/2015/lei/113089 . Acesso em: 07/2019.

BRASIL. LEI № 13.683, DE 19 DE JUNHO DE 2018. Altera as Leis n o ${ }^{\mathbf{0}} \mathbf{1 3 . 0 8 9}$, de 12 de janeiro de 2015 (Estatuto da Metrópole), e 12.587, de 3 de janeiro de 2012, que institui as diretrizes da Política Nacional de Mobilidade Urbana. Brasília-DF: Palácio do Planalto, 2018. Disponível em: http://www.planalto.gov.br/ccivil_03/_Ato2015-2018/2018/Lei/L13683.htm. Acesso: 07/2019.

CEARÁ. Lei Complementar №168, 27 de dez. de 2016. Criação da Região Metropolitana de Sobral. Fortaleza-CE, dez. 2016. 
FIRKOWSKI, O. L. C. F. Metrópoles e Regiões metropolitanas no Brasil: conciliação ou divórcio? In: FURTADO, Bernardo Alves; KRAUSE, Cleandro; FRANÇA, Karla Christina Batista de (Orgs.). Território Metropolitano, políticas municipais: por soluções conjuntas de problemas urbanos no âmbito metropolitano. Brasília: IPEA, 2013, p. 21-51.

IBGE - Instituto Brasileiro de Geografia e Estatística. Regiões de Influência de Cidades 2007 - REGIC. Rio de Janeiro: IBGE, 2008.

IBGE - Instituto Brasileiro de Geografia e Estatística. Regiões de Influência de Cidades 2018 - REGIC. Rio de Janeiro: IBGE, 2020.

IBGE. Estimativa populacional - 2020. Disponível em:

$<$ https://www.ibge.gov.br/estatisticas/sociais/populacao/9103-estimativas-depopulacao.html?=\&t=o-que-e $>$ Acesso em: 28/06/2021.

IPECE - Instituto de Pesquisa Econômica do Ceará. PIB dos municípios cearenses 2016. Disponível em:

https://www.ipece.ce.gov.br/wpcontent/uploads/sites/45/2018/12/ipece_informe_142_ 17_Dez2018.pdf Acesso: 28/06/2021.

LENCIONI, S. Reconhecendo metrópoles: sociedade e território. In: SILVA, Cátia Antonia, et. al (Orgs). Metrópole: governo, sociedade e território. Rio de Janeiro: DP\&A, 2006.

MEDEIROS, M. A. A quebra do sistema produtivo do semiárido: o caso de Cariré. Trabalho de Conclusão de Curso (Graduação em Geografia) - Centro de Ciências Humanas, Universidade Estadual Vale do Acaraú. Sobral, 2000. 98p.

PDUI/RMS. Plano de Desenvolvimento Urbano Integrado da Região Metropolitana de Sobral. Relatório final. Fortaleza: Governo do Estado do Ceará/ Consórcio PLANMETRO. 1163p.

RODRIGUES, A. V.; SALES, T. B.; TELES, G. A. O comércio na cidade pequena: a relação entre Cariré-Varjota no Ceará. Revista Homem, Espaço e Tempo, v. 11, p. 5777, 2018.

SANTANA, A. N. C. Pequenas cidades do Ceará no (des) encontro do urbano e do rural: Groaíras e Meruoca em discussão. Tese (Doutorado em Geografia) - Centro de Geociências, Universidade Federal Fluminense. Rio de Janeiro, p. 235, 2011.

SILVA, M. I. F.; HOLANDA, V. C. C. Um estudo dos circuitos da economia urbana na cidade de Cariré - CE. Revista Homem, Espaço e Tempo, v. 3, p. 52-71, 2009.

SOARES, P. R. R. Regiões metropolitanas ou aglomerações urbanas: contribuição para o debate no Rio Grande do Sul. Ensaios (FEE), v. 36, p. 323-342, 2015.

RODRIGUES, A. V. Cidades médias no contexto metropolitan brasileiro: institucionalização e planejamento territorial da Região Metropolitana de 
Sobral/CE. Dissertação (Mestrado em Geografia) - Centro de Ciências Humanas, Universidade Estadual Vale do Acaraú. Sobral, 2020, 205p.

RODRIGUES, A.V. Da institucionalização à construção do PDUI: as diretrizes da reestruturação territorial da Região Metrolitana de Sobral (Ceará - Brasil). Revista Equador, Vol. 9, № 2, p.189 - 214. 2020.

RODRIGUES, A. V.; TELES, G. A.; SALES, T. B. A institucionalização da Região Metropolitana de Sobral (CE): disparidades socioeconômicas e integração em questão. In: XIII Encontro Nacional da Associação Nacional de Pós-Graduação e Pesquisa em Geografia, São Paulo. Anais (...) São Paulo: ANPEGE, 2019.

TELES, Glauciana Alves. Dinâmicas metropolitanas contemporâneas: Caucaia na Região Metropolitana de Fortaleza. Dissertação de Mestrado. Mestrado Acadêmico em Geografia, Universidade Estadual do Ceará, Fortaleza, 2005.

TELES, Glauciana Alves. Mobilidade, trabalho e interações socioespaciais: $O$ Complexo Industrial e Portuário do Pecém no Contexto da Região Metropolitana de Fortaleza. Tese de doutorado. Pós-graduação em Geografia da Universidade Estadual do Ceará, Fortaleza, 2015.

Autor 1: Elaboração, discussão dos resultados, pesquisa bibliográfica e documental, pesquisa de campo, revisão do texto Autor 2: Supervisão, análise final dos resultados e revisão do texto 